\title{
As interações entre Relações Internacionais e Migrações Internacionais e os desafios para a soberania do Estado no atual contexto globalizado
}

\author{
Leonir Mário Chiarello *
}

No atual contexto de globalização, as teorias sobre relações internacionais concentraram sua atenção nos debates sobre a melhor forma de inserir os Estados nacionais no novo contexto global. Assim, só recentemente preocuparam-se com os movimentos de pessoas que ocorrem entre os territórios dos próprios Estados. Por outro lado, as teorias sobre as migrações internacionais voltaramse para as dimensões econômicas, sociológicas, políticas e culturais dos fluxos internacionais de pessoas, sem o desenvolvimento de uma reflexão específica sobre a interação entre as migrações e as relações internacionais. Diante desta problemática, a pergunta que norteará este artigo será: por que existe essa falta de interação entre migrações e relações internacionais, e quais são os fatores e as consequências envolvidos nesta falta de interação?

Nossa hipótese sustenta que a limitada interação entre relações internacionais e o fenômeno das migrações é determinada pelo paradigma estatal e nacional, através do qual se definem as teorias sobre as relações internacionais e as migrações, apesar da natureza transnacional da última. Para superar o determinismo de tal paradigma estatal, nossa segunda hipótese propõe a governança global das migrações, que inclui as relações internacionais como o instrumento mais adequado para permitir uma maior interação entre os dois aspectos.

O nosso objetivo é mostrar que as migrações internacionais são um fenômeno intrinsecamente transnacional e que, portanto, requerem políticas

* Diretor Executivo da Rede Internacional Scalabriniana de Migrações - SIMN. 
internacionais e supranacionais. Para este fim, consideramos três aspectos essenciais, relacionados às migrações e às relações internacionais: a) interações teóricas e práticas entre relações internacionais e migrações internacionais, b) perspectivas unilaterais e multilaterais através das quais são consideradas as relações internacionais e as migrações internacionais e c) governança global das migrações como um novo paradigma de interação entre as relações internacionais e as migrações internacionais.

\section{Interações entre relações internacionais e migrações}

Numa breve análise das interações entre relações internacionais e migrações, não pretendemos apresentar de maneira exaustiva as várias teorias sobre migrações e relações internacionais, mas, após breve introdução sobre as diferentes perspectivas através das quais estas são consideradas, apresentar os principais elementos de interação entre elas no atual contexto mundial.

\section{Perspectivas teóricas sobre as migrações internacionais}

As principais perspectivas a partir das quais se interpretam hoje as migrações internacionais são a econômica, a sociológica e a política, em que diversas teorias tentam fornecer explicações sistemáticas para este fenômeno ${ }^{1}$. Considerando que os fatores econômicos são os que determinam em grande parte os movimentos migratórios, as teorias econômicas são as mais desenvolvidas, destacando-se entre elas as teorias neoclássicas micro e macroeconômicas, a teoria da nova economia da migração, a teoria do mercado de trabalho dual e a teoria histórico-estrutural (BODVARSSON e VAN DER BERG, 2009). Privilegiando os fatores relacionados à estrutura social e à qualidade de vida dos migrantes, as teorias sociológicas, como a teoria dos fatores de expulsão e atração (push and pull factors), a teoria do sistema mundo, a teoria das redes, a teoria institucional, a teoria da causalidade cumulativa e a teoria dos sistemas de migração querem superar a visão economicista das migrações, investigando os fatores pessoais, grupais e culturais envolvidos nos processos migratórios (MASSEY et al., 2006). Enquanto isso, as teorias políticas, como a teoria neorrealista, a teoria pluralista e a teoria da economia política internacional, tentam explicar não apenas as causas, mas também os efeitos das migrações sobre os Estados e a influência desses últimos sobre os fluxos migratórios (PHILLIPS, 2011). No entanto, autores como Stephen Castles e Mark Miller afirmam que é impossível explicar a migração internacional a partir de causas únicas ou de forma simplista tal como a maior parte dessas teorias pretende fazer (CASTLES e MILLER, 1993). Para eles, cada movimento migratório tem características específicas e se desenvolve sob circunstâncias históricas particulares e, portanto, devem ser consideradas como o resultado da interação das estruturas micro e macro. As primeiras se referem a fatores específicos, tais como a conformação de redes migratórias, crenças e 
práticas dos próprios migrantes, e as segundas a fatores mais gerais, tais como a economia política global e políticas estatais e interestatais, que influenciam as relações internacionais (MILLER e DENEMARK, 1993, p. 2-3).

\section{Paradigmas de Relações Internacionais}

Com contribuições, principalmente da história, do direito e da diplomacia, a reflexão sobre as relações internacionais foi marcada por constantes tensões e debates entre três grandes correntes clássicas de pensamento: a kantiana ou idealista, a hobbesiana ou realista e a grociana ou da sociedade internacional ${ }^{2}$. Esses debates, que representam a tentativa incansável de adaptar o estudo das relações internacionais às novas realidades e transformações que a realidade internacional experimenta, desembocaram nos três maiores paradigmas ou modelos teóricos clássicos em torno dos quais se estruturou o pensamento e a construção teórico-metodológica das relações internacionais até hoje: o idealismo, o realismo e o pluralismo ou paradigma de interdependência (BURCHILL et al., 2001; WEBER, 2010).

O idealismo, que surge como proposta interpretativa das relações internacionais no contexto da Primeira Guerra Mundial, parte da premissa de que o homem tende inerentemente à cooperação, por isso as relações internacionais não se encontram num contexto de conflito permanente entre os Estados, mas naqueles laços sociais transnacionais que são tecidos constantemente entre os indivíduos. Sob este ponto de vista, a política internacional é o reflexo da tendência natural para a cooperação e a progressiva harmonia de interesses que conduzem à organização do mundo, em que o direito internacional desempenha um papel fundamental na constituição de uma sociedade internacional. De acordo com este paradigma, foi desenvolvida a tradição do liberalismo nas relações internacionais em suas várias expressões (o liberalismo sociológico, institucional ou republicano), bem como o neoliberalismo (JACKSON e SORENSEN, 2003; WEBER, 2010, p. 37-60).

Ao contrário, o realismo, proveniente de uma escola de pensamento antropológico pessimista, considera que a política internacional pode ser melhor descrita como um estado de guerra permanente. A partir dessa perspectiva, as relações internacionais são interpretadas como conflitantes na essência, concentrando-se em questões tais como a guerra, a ordem e a segurança, a defesa da soberania nacional, fatores que, por sua vez, serão considerados o suporte do exercício da diplomacia. Sob esta visão de mundo, os Estados são os atores únicos e primordiais das relações internacionais, concebidos como unidades coerentes e racionais em suas ações e na defesa do interesse nacional em relação ao exterior (BURCHILL et al., 2001, p. 70-102). Em consonância com esta perspectiva realista, a partir da década de 1970, surge o paradigma da interdependência, que reconhece a natureza complexa da realidade internacional e afirma que as relações internacionais não podem ser interpretadas exclusivamente a partir das relações 
interestaduais e dos problemas de segurança entre os países, mas que devem considerar uma diversidade de atores, problemáticas e canais que conectam as sociedades e as transformam numa sociedade internacional de caráter mundial ou global (DUNNE, KURKI e SMITH, 2007; WEBER, 2010, p. 13-36).

A partir de uma perspectiva diferente das anteriores, o paradigma estruturalista parte do questionamento do status quo do sistema internacional, baseado no capitalismo e nas relações assimétricas de poder entre os Estados ricos e exploradores, por um lado, e os pobres e explorados, por outro. $\mathrm{O}$ estruturalismo postula a superação dessa dicotomia e o estabelecimento de uma sociedade internacional livre dos Estados, até agora considerados como representantes do capitalismo e dos interesses das classes dominantes, mediante a ação revolucionária dos setores explorados. A partir do paradigma estruturalista, surgem diferentes teorias das relações internacionais, entre as quais a teoria do sistema capitalista mundial e a teoria da dependência, esta representada por vários pensadores latino-americanos ${ }^{3}$.

Os paradigmas apresentados acima surgiram em contextos específicos, interagindo antagonicamente uns com os outros, em alguns casos, ou de forma dialógica na maior parte deles, gerando novas teorias como o neorrealismo, o neoliberalismo ou o neoestruturalismo, para citar alguns, e a inclusão de novas temáticas na agenda das relações internacionais, tais como o meio ambiente, os direitos humanos e as questões de gênero. Apesar deste dinamismo no debate teórico sobre as relações internacionais e a inclusão de novos aspectos de importância internacional, a questão das migrações internacionais continua sendo excluída da análise.

\section{Interação entre os paradigmas de relações internacionais e as migrações}

O aumento contínuo das migrações internacionais nas últimas décadas está provocando um impacto significativo nas relações internacionais. Se a população de migrantes continua aumentando no mesmo ritmo dos últimos vinte anos, o contingente atual de 215 milhões de migrantes internacionais em todo o mundo poderia atingir 405 milhões em 2050, segundo as previsões da Organização Internacional para as Migrações (OIM, 2010, p. 3). Este incremento dos fluxos migratórios afeta não apenas os países emissores e receptores de migrantes, mas também os de trânsito. As reações diante desse aumento podem ser muito diferentes, tanto em nível político e jurídico como social, comprometendo as relações dos Estados entre si. As políticas ou ações domésticas ou internacionais que os Estados implementam têm impactos inevitáveis sobre a migração internacional. As normas permissivas, restritivas ou seletivas implementadas pelos países receptores para regular a entrada de imigrantes, e implementadas pelos países emissores para facilitar ou restringir a saída de emigrantes, têm consequências diretas sobre o volume e a qualidade (regular ou irregular) das migrações internacionais (WEINER, 2006, p. 89-102). Por outro lado, a migração 
pode influenciar e também ser utilizada pelos Estados para obter certos objetivos da sua própria política interna ou externa. Isso mostra como, no contexto internacional atual, as migrações e as relações internacionais se mesclam e interagem mutuamente. Dependendo da perspectiva de onde os atores políticos e sociais, incluindo os pesquisadores, interpretem essa interação, poderão propor uma interação de conflito ou de cooperação entre ambas (MITCHELL, 1989, p. 682-683).

Apesar da natureza transnacional das migrações e os impactos recíprocos entre migrações e relações internacionais, a maioria dos estudiosos concorda ao afirmar que é muito limitada a análise que a disciplina das relações internacionais desenvolveu em relação aos movimentos internacionais de população. Alguns autores expressam preocupação ao estudar a migração a partir da perspectiva das relações internacionais. Tratam-se, no entanto, de esforços isolados e longe do núcleo do estudo da disciplina, na qual a migração internacional é considerada como um tópico específico de estudo (WEINER, 2006, p. 89-90).

Baseado no fato acima e na constatação de que o movimento de pessoas através das fronteiras é um fenômeno intrinsecamente transnacional e, portanto, afeta as relações internacionais, consideramos importante investigar a forma como interagem os paradigmas das relações internacionais e as teorias sobre migração para garantir uma melhor governabilidade das migrações internacionais. Para isso e considerando o limite de nosso estudo, examinaremos brevemente três paradigmas clássicos das relações internacionais e suas possíveis contribuições à reflexão sobre as migrações internacionais: o realismo, a interdependência e o estruturalismo.

O realismo é conhecido por dar importância central ao Estado-nação, que considera uma unidade compacta e racional, cujo ato é sempre motivado pela defesa do interesse nacional. Este interesse nacional está associado principalmente à segurança e ao poder, porque são estes dois elementos que garantem a sobrevivência dos Estados em um mundo que é concebido como hostil e anárquico. $O$ enrijecimento das políticas migratórias que os países desenvolvidos empreenderam nas últimas décadas ou o fortalecimento das fronteiras físicas através de controles fronteiriços mais rígidos e/ou a construção de muros, tudo feito em base ao argumento de desencorajar ou controlar a crescente imigração irregular proveniente de países pobres, são manifestações da interpretação da imigração como uma questão de segurança. Na verdade, a imigração, especialmente a irregular, é percebida como uma ameaça em sociedades como aquelas dos Estados Unidos e da Europa, e os Estados fecham diante dela suas fronteiras para garantir a segurança nacional, bem como a segurança societal de suas nações ${ }^{4}$. A construção de muros entre a Índia e o Paquistão na Caxemira, entre a Arábia Saudita e o lêmen, entre a Malásia e a Tailândia, entre o Quirguistão e o Uzbequistão e entre os Estados Unidos e o México, para citar alguns exemplos, não só revela a contradição com o discurso atual da globalização, que defende fronteiras abertas à circulação de 
bens, capitais e serviços, mas também o temor ou a rejeição do ingresso dos "indesejados" (MÁRMORA, 2009, p. 292-293). Apesar da força com que essas ações restritivas à imigração se propagaram no que poderíamos definir como a predominância de medidas realistas frente às migrações internacionais, a maioria dos especialistas em questões migratórias afirma que o realismo não é adequado para analisar o fenômeno da migração internacional e é ineficiente para garantir governabilidade migratória no longo prazo, devido a duas razões principais. Primeiro, com o avanço do processo de globalização, os Estados reconhecem que suas fronteiras estão cada vez mais porosas e frágeis e que, por mais que tentem fechá-las diante de uma imigração não desejada, esta vai continuar aparecendo de forma irregular. Em segundo lugar, na medida em que a migração não é analisada como fenômeno multicausal, qualquer ação restritiva torna-se ineficiente por não apontar as causas que geram o deslocamento de pessoas através das fronteiras (MILLER e DENEMARK, 1993, p. 40-41).

A partir de uma perspectiva diferente, considerando as características e dinâmicas docrescente processo deglobalização, oparadigmadainterdependência descreve a realidade internacional como cenário cada vez mais complexo e transnacional, em que o confronto político-militar-ideológico da ordem bipolar (ou high politics) acabou relegado ao passado, diante da ascensão de múltiplos atores, temáticas e desafios (low politics) igualmente importantes, entre os quais os econômicos, ambientais, sociais e culturais. A partir desta perspectiva, a migração internacional entra na agenda global como uma preocupação especial dos Estados, organismos intergovernamentais e organizações nãogovernamentais. Neste sentido, o paradigma da interdependência é muito mais adequado para refletir sobre o fenômeno das migrações internacionais. Além disso, considerando o seu interesse particular em estudar a conformação de novos e múltiplos regimes internacionais, sejam esses institucionalizados ou não, no tratamento de vários temas vinculados às relações internacionais na ordem global, o paradigma da interdependência tornou-se a fonte de inspiração para a promoção de um regime que, apesar de ser ainda informal, está discutindo, de forma específica, a questão da governabilidade migratória. O Fórum Global sobre Migrações e Desenvolvimento e, em nível de América Latina, a Conferência Sulamericana sobre Migrações, bem como a Conferência Regional sobre Migrações da América do Norte e América Central, são, entre outros, alguns exemplos de emergentes regimes internacionais sobre migração (MITCHELL, 1989, p. 684685). Por outro lado, e não obstante o acima referido, o peso transcendental que a visão da interdependência dá aos fatores econômicos e comerciais distorce ou limita a análise da migração internacional à mobilidade de mão de obra, embora esta seja um fator mais de intercâmbio no mercado global. Sem dúvida, tal como observamos anteriormente, a migração internacional tem uma natureza muito mais complexa (MILLER e DENEMARK, 1993, p. 41).

O paradigma estruturalista, particularmente examinado sob o prisma da teoria do sistema-mundo, fornece explicações valiosas para a análise das causas 
dos atuais movimentos significativos de pessoas de países pobres para os mais desenvolvidos. O desenvolvimento desigual entre o Norte e o Sul (ou entre o centro e a periferia) do mundo é uma variável fundamental para a teoria do sistema-mundo, através da qual se pode explicar a tendência atual das migrações internacionais, caracterizadas principalmente pelas migrações Sul-Norte. A teoria do sistema-mundo argumenta que a longa história de exploração do Sul pelas potências europeias durante a era colonial e, posteriormente, dos Estados Unidos, levou ao estabelecimento de um sistema de desenvolvimento desigual que se manifesta nas grandes diferenças de renda, de acesso à saúde, educação, segurança e outros serviços sociais, entre os cidadãos de países desenvolvidos e os em desenvolvimento. Esta progressiva deterioração dos termos de intercâmbio entre os países do Norte, que dominam e exploram os países do Sul, gerando nos países do Sul uma situação de pobreza, desigualdade social, ambientes políticos instáveis e violentos e crises ambientais, são incentivos determinantes para que as pessoas emigrem. Neste sentido, a teoria do sistema-mundo, mais claramente do que as outras teorias, salienta os elementos do contexto em que se desenvolvem os movimentos migratórios, incluindo suas causas e consequências, e é a que deu origem a uma teoria específica de interpretação dos movimentos migratórios, a teoria do sistema de migração (MILLER e DENEMARK, 1993, p. 43). No entanto, embora esta visão crítica das relações internacionais contribua significativamente para identificar os fatores que causam a migração internacional, seu limite está em não oferecer possíveis soluções ou alternativas para reverter as próprias causas que levam à maciça migração Sul-Norte, além de não considerar adequadamente outros fatores que não sejam os econômicos ou das migrações internacionais, tais como, por exemplo, os regulamentos permissivos ou restritivos para a entrada e saída de migrantes, implementados pelos Estados, que também são fatores determinantes dos fluxos migratórios (MITCHELL, 1989, p. 686).

\section{As opções do unilateralismo e do multilateralismo}

O aumento dos fluxos migratórios dos países pobres para os ricos, experimentado desde a década de 1980, associado às altas taxas de imigração irregular (cerca de 11 milhões nos Estados Unidos e 6 milhões na Europa, atualmente) (MIRKIN, 2011, p. 9), gerou fortes tensões em torno do fenômeno da migração internacional. As diversas políticas que os Estados implementaram para enfrentar esses fluxos migratórios estão fortemente determinadas pela situação em que os países se encontram: países emissores, receptores ou de trânsito de migrações. Neste sentido, enquanto os Estados receptores tendem a aplicar medidas restritivas e discricionárias, que justificam como decisões de âmbito doméstico, os emissores promovem medidas de negociação, tanto em nível bilateral, quanto multilateral. Tratase, porém, de caminhos claramente opostos. 
O principal argumento subjacente à postura unilateral é que as migrações corroem a capacidade dos países receptores de controlar suas fronteiras, o que é agravado pelo contexto econômico global que lhes exige abrir-se sem restrições ao intercâmbio de capitais, bens, serviços e tecnologia. O controle da entrada, saída e permanência de pessoas no território nacional é, assim, considerado como uma das prerrogativas últimas de um Estado para garantir sua soberania territorial. Neste sentido, a reação radical e unilateral do fechamento das fronteiras obedece ao que alguns autores chamam de modelo de securitização, a partir do qual a gestão da imigração concentra-se na proteção da segurança nacional, social, cultural e do trabalho da população nativa (MÁRMORA, 2009, p. 288-294). As percepções negativas sobre os imigrantes, especialmente os imigrantes irregulares, promovidas por vários atores sociais e assumidas pelos Estados, associam as migrações a atividades criminosas ou terroristas, considerando-as como uma ameaça à segurança nacional, bem como uma ameaça para a identidade cultural e o estilo de vida próprios do país receptor. Em outros casos, a entrada de irregulares, vindos de países pobres, é vista como um obstáculo ao crescimento econômico e social do país receptor, porque se supõe que são os imigrantes os que usam os serviços sociais, como educação e saúde, representando uma carga financeira adicional e afetando a população autóctone ao acesso a esses serviços (MÁRMORA, 1997, p. 53-64). A manifestação mais concreta de gestão unilateral e pró-securitização da imigração encontra-se nas políticas implementadas pelos países desenvolvidos, como os Estados Unidos e os países europeus. Apelando para o direito soberano de proteger suas fronteiras contra a ameaça do terrorismo internacional, suas políticas migratórias se concentraram, principalmente durante a última década, nas restrições à entrada e permanência de imigrantes, além de punir com a deportação, ou mesmo com penas carcerárias, a imigração irregular, catalogada como crime. A Diretiva de Retorno, aprovada pela União Europeia em 2008, a lei que criminaliza a imigração irregular na Itália e a controversa lei 1070, implementada no Estado do Arizona, Estados Unidos, em 2010, são alguns exemplos dessas medidas unilaterais restritivas (KOLOWSKI, 2011).

O multilateralismo, embora menos difundido do que o unilateralismo, é a alternativa apoiada principalmente pelos países emissores de migrantes, os organismos internacionais e as organizações da sociedade civil comprometidas com a proteção dos direitos humanos dos migrantes. A partir da perspectiva do multilateralismo, podem-se distinguir dois modelos específicos de governabilidade migratória: o modelo de benefícios compartilhados, que considera as migrações como uma variável de ajuste do mercado de trabalho e que, portanto, podem ser benéficas tanto para os países receptores como também para os emissores, e o modelo de desenvolvimento humano das migrações, que propõe a centralidade da pessoa humana que migra, através da proteção do direito ao desenvolvimento das pessoas, para que não tenham que migrar, e o direito de participação nos benefícios do desenvolvimento dos países 
de destino, para pessoas que já migraram, com direitos iguais aos dos cidadãos nacionais (MÁRMORA, 2009, p. 288-294).

No âmbito formal, a escolha do multilateralismo na gestão da migração internacional não conta com um órgão específico no interior das Nações Unidas, e o único marco jurídico multilateral é a Convenção Internacional sobre a Proteção dos Direitos de Todos os Trabalhadores Migrantes e Membros de suas Famílias de 1990, que não foi ratificada por nenhum dos atuais países receptores de migrantes. Alguns aspectos da regulamentação multilateral das Nações Unidas, referentes aos refugiados, aos direitos trabalhistas dos migrantes e aos direitos humanos das pessoas, podem servir como elementos implícitos de gestão dos fluxos migratórios, porém, a ausência de um marco regulatório e de uma instituição responsável em nível multilateral impede uma governabilidade migratória global, como discutiremos na terceira parte de nosso artigo (KOSER, 2010; BHAGWATI, 2003). Devido a esta falta de um marco regulatório e de instituições supranacionais, com exceção da União Europeia, os países que escolheram a perspectiva do multilateralismo promoveram a criação de espaços comuns de diálogo e cooperação bilateral e regional, com o apoio da Organização Internacional para as Migrações (OIM), que, embora não vinculativos, permitiram avançar na definição consensual das migrações em nível multilateral, como a Conferência Sul-Americana sobre Migrações, o Processo de Puebla para os países da América Central e América do Norte, o Processo de Budapeste para os países do Leste Europeu, o Processo de Bali para a Austrália e os países do Sudeste Asiático e os Diálogos Regionais sobre Migrações do Oeste e Sudeste da África, para citar alguns exemplos (HANSEN, 2010).

\section{Rumo a uma governança global das migrações}

A busca de soluções unilaterais ou multilaterais aos crescentes desafios que as questões globais trazem, tais como as referentes às migrações internacionais, revela que as instituições e normas Estado-cêntricas não têm a capacidade necessária para tratar adequadamente estes desafios, derivados do crescente processo de globalização. Esta falta de eficácia e eficiência na gestão de um fenômeno transnacional tão complexo como as migrações pode causar o que alguns autores definem como a desgovernabilidade migratória (MÁRMORA, 1997, p. 45-47).

Diante deste desafio, desde a década de 1990, a governança global mergulhou em uma nova perspectiva (que alguns autores chegam a propor como novo paradigma nas relações internacionais), através da qual se procura definir soluções e garantir a governabilidade de diferentes questões transnacionais, diante da ausência de um governo mundial ${ }^{5}$. A partir desta perspectiva, a governança global não se confunde mais com um governo mundial, mas com a soma de leis, regulamentos, políticas e instituições que definem, constituem e mediam as relações transnacionais entre Estados, cidadãos, organizações 
intergovernamentais e não-governamentais, bem como também o mercado. Neste sentido, a governança global, não querendo substituir o papel dos Estados, não se limita à cooperação interestatal, mas propõe a busca por soluções e a governabilidade de problemas transnacionais através de um sistema de cooperação entre os atores estatais, interestatais, supraestatais e a sociedade civil. As Conferências Mundiais promovidas pelas Nações Unidas, a partir da década de 1970, sobre meio ambiente, população, direitos humanos, mulheres, crianças, desenvolvimento social, segurança alimentar, racismo ou AIDS, são alguns dos exemplos dessa busca por soluções institucionais com base no consenso e coordenadas entre os atores do Estado para os crescentes problemas transnacionais. Estas podem ser definidas como iniciativas de governança global interestatal (HELD e McGREW, 2002). Por outro lado, existem áreas específicas de governança global que superam o direito internacional público, nas quais os atores não-estatais colaboram na negociação, implementação, acompanhamento e execução de normas internacionais a partir do direito contratual privado, como é o caso das normas do ISO (International Organization for Standardization), para citar um exemplo (MASCAREÑO, 2007).

Apesar do desenvolvimento da cooperação internacional institucionalizada para esses problemas transnacionais através do sistema das Nações Unidas e o estabelecimento de acordos internacionais, geralmente supervisionados por organizações internacionais, como mencionado acima, não há uma estrutura institucional formal e coerente para regular as políticas dos Estados frente à migração internacional. Embora haja uma Organização Internacional para as Migrações (OIM), que lida com as políticas e programas internacionais sobre migrações, esta permanece fora do sistema das Nações Unidas. A inexistência de uma organização específica para as migrações dentro do sistema das Nações Unidas, como há para questões de comércio, saúde, educação, direitos humanos, crianças e refugiados, para citar alguns exemplos, somado à existência de um regime migratório internacional informal e limitado em seu alcance, revela que os Estados soberanos continuam mantendo uma autonomia determinante na definição e implementação de suas políticas migratórias.

Devido a esta ausência de um marco e de instituições multilaterais, os Estados desenvolveram nas últimas décadas, com a participação e o apoio de entidades da sociedade civil, várias iniciativas ad hoc de governança das migrações em diferentes níveis: bilateral, regional e inter-regional, e trabalharam em várias questões relacionadas às migrações, tais como saúde, educação, direitos trabalhistas e segurança social. Isso, no entanto, revela um tratamento indireto e fragmentado do complexo fenômeno das migrações, que exige, pelo contrário, um tratamento específico e holístico ${ }^{6}$.

As iniciativas promovidas pela Organização das Nações Unidas não conseguiram nem o consenso nem a institucionalidade necessária para o estabelecimento de uma governabilidade global das migrações. A proposta de um grupo de países em desenvolvimento de realizar uma Conferência Mundial 
sobre as Migrações, apresentada na Conferência Mundial de População, no Cairo, em 1994, foi fortemente rejeitada pelos países desenvolvidos. As propostas institucionais da Comissão Global sobre Migração Internacional (criada em 2003), apresentadas no Diálogo de Alto Nível sobre Migrações e Desenvolvimento, realizado em 2006, também foram rejeitadas pelos países desenvolvidos, que apoiaram a criação do Fórum Global sobre Migrações e Desenvolvimento, que se realiza anualmente desde 2007. Embora seja um espaço de reflexão global e de cooperação em matéria de migrações internacionais, o Fórum continua sendo de caráter não-vinculante (BETTS, 2011, p. 1-3).

Do ponto de vista acadêmico, alguns projetos de pesquisa refletiram sobre a arquitetura institucional global mais adequada para a gestão e tratamento da migração internacional, entre os quais se destacam a proposta de Bimal Ghosh (2000), para um novo regime internacional sobre migrações e a proposta de um regime de mobilidade global, de Rey Koslowski (2008). Apesar dos avanços destas novas discussões, tanto o âmbito acadêmico, quanto o político das relações internacionais negligenciam aspectos essenciais da governança global das migrações, tais como os elementos institucionais, políticos e regulatórios, ou a cooperação internacional para regular as migrações (NEWLAND, 2010).

\section{Conclusão}

O aumento das migrações internacionais e o caráter de irregularidade com que se revestem geram tensões entre os países emissores, receptores e de trânsito dos migrantes. De maneira semelhante a outras questões transnacionais como o meio ambiente, os direitos humanos e o crime organizado, para citar alguns exemplos, as migrações internacionais afetam simultaneamente o âmbito doméstico e o internacional, ultrapassando as fronteiras nacionais. Neste sentido, as medidas unilaterais que os países desenvolvidos estão promovendo na atualidade resultam ineficazes para garantir a governabilidade de um fenômeno de natureza inerentemente transnacional. Além disso, as políticas migratórias implementadas a partir da perspectiva exclusiva da securitização são insustentáveis no longo prazo, porque não consideram as causas da migração, tais como a pobreza, a desigualdade e a falta de oportunidades, entre outras, e tampouco levam em conta as suas consequências, como a irregularidade migratória e a consequente vulnerabilidade social dos migrantes.

Esta predominância de políticas migratórias restritivas revela que a gestão das migrações internacionais é determinada pelo paradigma estatal e nacional. Consequentemente, as iniciativas multilaterais são fracas e fragmentadas, além de contar com a oposição dos países mais poderosos e desenvolvidos. Neste contexto, a disciplina de relações internacionais pode contribuir para a formulação de propostas teóricas e de políticas tendentes a garantir uma governabilidade das migrações mais adequada às exigências atuais do mundo globalizado. 
Tudo isso requer uma maior interação entre a teoria e a prática das relações internacionais com as migrações internacionais e as teorias que buscam interpretar estas últimas. As atuais iniciativas sobre essa interação são limitadas e estão fracionadas. Sem dúvida, a perspectiva de uma governança global das migrações pode se transformar numa estratégia adequada para fortalecer essa interação e incluir a questão das migrações na agenda teórica e prática das relações internacionais. $O$ fortalecimento dessa interação pode abrir novos caminhos, não só para garantir uma governabilidade mais eficiente das migrações internacionais, mas também para uma maior legitimidade das relações internacionais, ao integrar em suas agendas a proteção da dignidade e dos direitos dos migrantes e suas famílias.

\section{Notas}

1 - Para uma visão ampla das teorias sobre as migrações internacionais, cf. Brettell e Hollifield (2000) e Portes e DeWind (2007).

2 - Para uma visão exaustiva sobre a evolução histórica da disciplina das relações internacionais e os principais paradigmas que estruturaram a reflexão teórica sobre a mesma, cf. Dunne, Kurki e Smith (2007) e Ortiz (2000).

3 - Para uma síntese das teorias das relações internacionais, incluindo uma análise específica da teoria da dependência, cf. Tomassini (1989, p. 98-110) e Weber (2010, p. 61-82).

4 - As duas dimensões de segurança, nacional e societal, são propostas por Samuel Huntington (2005) em sua análise dos impactos da imigração latina na identidade dos Estados Unidos.

5 - Para uma visão exaustiva sobre a temática da governança global, cf. Weiss e Thakur (2010).

6 - Para uma visão exaustiva da governança global das migrações, cf. Betts (2011).

\section{Referências}

BETTS, Alexander (Editor). Global Migration Governance. Oxford: Oxford University Press, 2011.

BHAGWATI, Jagdish. Borders Beyond Control. Foreign Affairs, vol. 82. n 1, p. 98-104, 2003.

BODVARSSON, Örn e VAN DER BERG, Hendrik. The Economics of Immigration: Theory and Policy. New York: Springer Dordrecht, 2009.

BRETTELL, Caroline e HOLLIFIELD, James. Migration Theories: Talking Across Disciplines. New York: Routledge, 2000.

BURCHILL, Scott et al. Theories of International Relations. New York: Palgrave, 2001.

CASTLES, Stephen e MILLER, Mark. The Age of Migration. London: Macmillan, 1993.

DUNNE, Timothy; KURKI, Milja e SMITH, Steve. International Relations Theories: Discipline and Diversity. New York, 2007, p. 52-88.

GHOSH, Bimal. Managing Migration: Time for a new International Regime? Oxford: Oxford University Press, 2000.

HANSEN, Randall. An Assessment of Principal Regional Consultative Processes on Migration. Geneva: Organization of International Migration, 2010.

HELD, David e MCGREW, Anthony. Governing Globalization: Power, Authority and Global Governance. London: Wiley-Blackwell, 2002.

HUNTINGTON, Samuel. Who are We? The Challenges to America's National Identity. New York: Simon \& Schuster Paperbacks, 2005. 
JACKSON, Robert e SORENSEN, Georg. Introduction to International Relations. Theories and Approaches. Oxford: Oxford University Press, 2003, p. 106-137.

KOSLOWSKI, Rey. Global Mobility and the Quest for an International Migration Regime. In: CHAMIE, Joseph e DALL'OGLIO, Luca. International Migration and Development, Continuing the Dialogue: Legal and Policy Perspectives. New York: Center for Migration Studies, 2008, p. 103-144.

KOLOWSKI, Rey. Improving US and EU Immigration Systems: The Evolution of Border Controls as a Mechanism to Prevent Illegal Immigration. Washington DC: Migration Policy Institute, 2011.

KOSER, Khalid. International Migration and Global Governance. In: Global Governance, vol. 16, $\mathrm{n}^{\circ}$ 3, p. 301-316, 2010.

MÁRMORA, Lelio. Las políticas de Migraciones Internacionales. Buenos Aires: Alianza Editorial, 1997.

MÁRMORA, Lelio. Más allá de los muros nacionales: desafíos para convivencia pacífica. In: CHIARELLO, Leonir et al. (editores). Fronteras, ¿Muros o Puentes? Actas del Primer Fórum Internacional sobre Migración y Paz. New York: Scalabrini International Migration Network, 2009, p. 288-304.

MASCAREÑO, Aldo. Regímenes Jurídicos en la Constitución de la Sociedad Mundial. In: Política Criminal, no 4, A3, p. 1-39, 2007.

MASSEY, Douglas et al. Theories of International Migration: A Review and Appraisal. In: MESSINA, Anthony e GALLYA, Lahav (editors). The Migration: Exploring Politics and Policies. Londres: Lynne Rienner Publishers, 2006, p. 34-62.

MILLER, Mark e DENEMARK, Robert. Migration and World Politics: A Critical Case for Theory and Policy. New York: Center for Migration Studies, 1993.

MIRKIN, Barry. La migración internacional en el Hemisferio Occidental: un estudio exploratorio. New York: Scalabrini International Migration Network, 2011.

MITCHELL, Christopher. International Migration, International Relations, and Foreign Policy. In: International Migration Review, New York, vol. 23, no. 3, p. 681-708, 1989.

NEWLAND, Kathleen. The Governance of International Migration: Mechanisms, Processes, and Institutions. In: Global Governance, vol. 16, n³ 3, p. 331-344, 2010.

ORGANIZAÇÃO INTERNACIONAL PARA AS MIGRAÇÕES - OIM. Relatório mundial sobre a migração 2010. O futuro das migrações: reforço de capacidade para a mudança. Genebra: OIM, 2010.

ORTIZ, Eduardo. El Estudio de las Relaciones Internacionales. México D.F: Fondo de Cultura Económica, 2000.

PHILLIPS, Nicola (editor). Migration in the Global Political Economy. Londres: Lynne Rienner Publishers, 2011.

PORTES, Alejandro e DEWIND, Josh (editors). Rethinking Migration: New Theoretical and Empirical Perspectives. New York: Berghahn Books, 2007.

TOMASSINI, Luciano. Teoría y práctica de la política internacional: lecciones. Santiago de Chile: Ediciones Universidad Católica de Chile, 1989.

WEBER, Cynthia. International Relations Theory: A Critical Introduction. New York: Routledge, third edition, 2010.

WEINER, Myron. On International Migration and International Relations. In: MESSINA, Anthony e GALLYA, Lahav (editors). The Migration: Exploring Politics and Policies. Londres: Lynne Rienner Publishers, 2006, p. 89-102.

WEISS, Thomas e THAKUR, Ramesh. Global Governance and the United Nations: An Unfinished Journey. Bloomington: Indiana University Press, 2010. 


\title{
RESUMO
}

Este artigo mostra que a limitada interação entre as relações internacionais e o fenômeno das migrações é determinada pelo paradigma estatal e nacional através do qual se definem as teorias sobre as relações internacionais e as migrações, apesar da natureza transnacional destas últimas. Para superar o determinismo de tal paradigma estatal e nacional, o artigo propõe a governança global e ética das migrações internacionais como um novo paradigma de interação entre as relações internacionais e as migrações internacionais.

Palavras-chave: migrações; relações internacionais; governança global.

\begin{abstract}
This article highlights that the lack of interaction between international relations and international migration is determined by a statist and nationalist paradigm defining the theories of international relations and migrations, in spite of the transnational nature of migrations. To surpass the determinism of this statist and nationalist paradigm, the article proposes the global and ethical governance of international migration as a new paradigm of interaction between international relations and international migration.
\end{abstract}

Keywords: migrations; international relations; global governance. 